\title{
Long-Term Winter Inversion Properties in a Mountain Valley of the Western United States and Implications on Air Quality*
}

\author{
S.-Y. SIMON WANG \\ Utah Climate Center, and Department of Plants, Soil and Climate, Utah State University, Logan, Utah
}

LAWRENCE E. HIPPS

Department of Plants, Soil and Climate, Utah State University, Logan, Utah

OI-YU CHUNG

Utah Climate Center, Utah State University, Logan, Utah

ROBERT R. GILLIES

Utah Climate Center, and Department of Plants, Soil and Climate, Utah State University, Logan, Utah

RANDAL MARTIN

Utah Climate Center, and Department of Civil and Environmental Engineering, Utah State University, Logan, Utah

(Manuscript received 12 June 2015, in final form 18 August 2015)

\begin{abstract}
Because of the geography of a narrow valley and surrounding tall mountains, Cache Valley (located in northern Utah and southern Idaho) experiences frequent shallow temperature inversions that are both intense and persistent. Such temperature inversions have resulted in the worst air quality in the nation. In this paper, the historical properties of Cache Valley's winter inversions are examined by using two meteorological stations with a difference in elevation of approximately $100 \mathrm{~m}$ and a horizontal distance apart of $\sim 4.5 \mathrm{~km}$. Differences in daily maximum air temperature between two stations were used to define the frequency and intensity of inversions. Despite the lack of a long-term trend in inversion intensity from 1956 to present, the inversion frequency increased in the early 1980s and extending into the early 1990s but thereafter decreased by about $30 \%$ through 2013 . Daily mean air temperatures and inversion intensity were categorized further using a mosaic plot. Of relevance was the discovery that after 1990 there was an increase in the probability of inversions during cold days and that under conditions in which the daily mean air temperature was below $-15^{\circ} \mathrm{C}$ an inversion became a certainty. A regression model was developed to estimate the concentration of past particulate matter of aerodynamic diameter $\leq 2.5 \mu \mathrm{m}\left(\mathrm{PM}_{2.5}\right)$. The model indicated past episodes of increased $\mathrm{PM}_{2.5}$ concentrations that went into decline after 1990; this was especially so in the coldest of climate conditions.
\end{abstract}

\footnotetext{
* Supplemental information related to this paper is available at the Journals Online website: http://dx.doi.org/10.1175/JAMC-D15-0172.s1.
}

Corresponding author address: S.-Y. Simon Wang, Utah Climate Center, Utah State University, 4825 Old Main Hill, Logan, UT 84322.

E-mail: simon.wang@usu.edu

\section{Introduction}

The interior West of the United States has numerous mountain valleys, many of which are narrow. During winter, the combination of regional high pressure and snow-covered valley floors often produces optimal conditions for the formation of strong near-surface temperature inversions (hereinafter simply referred to as inversions). At local scales, these inversions are 
(a)
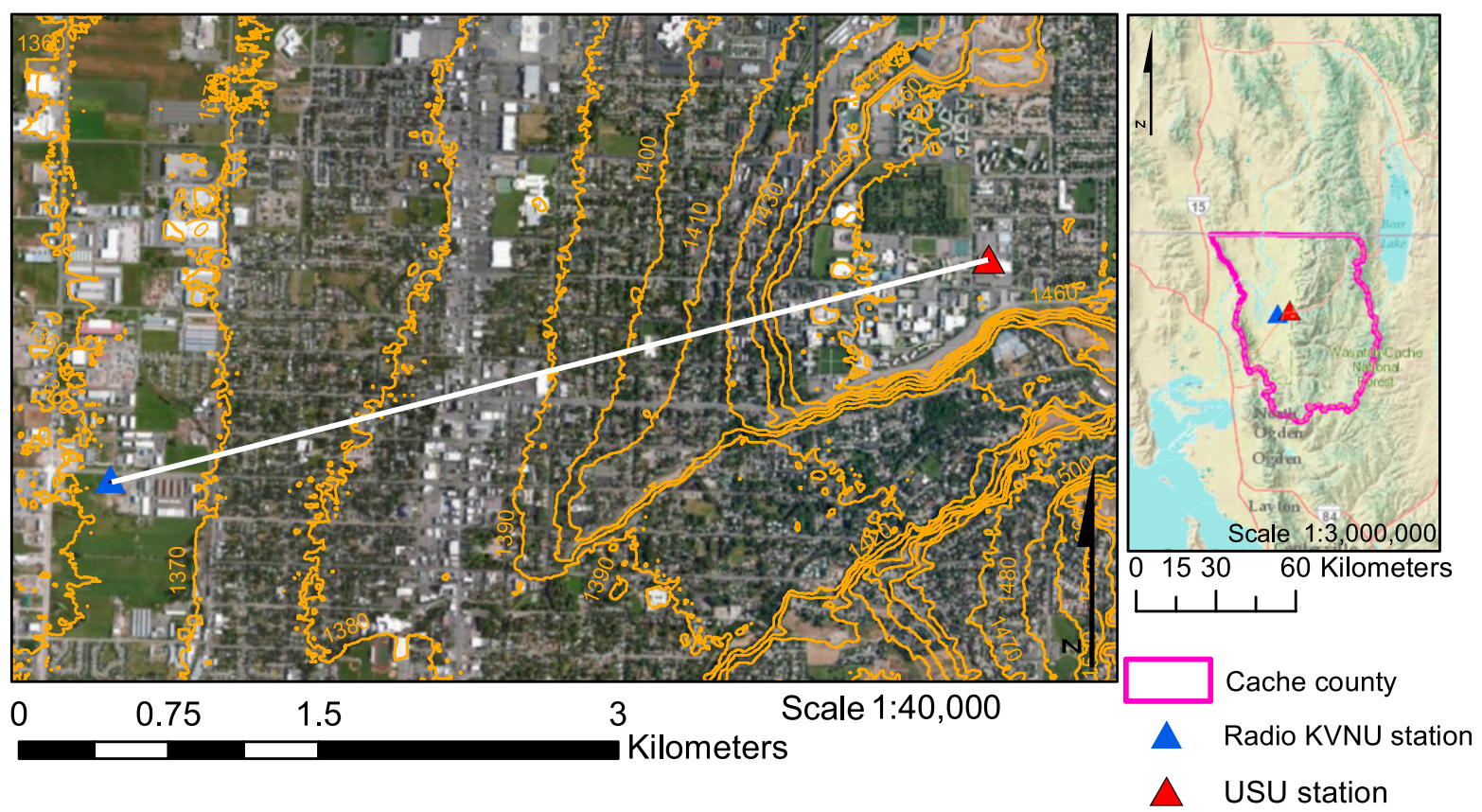

(b)

\section{Cross Section Profile between the stations}

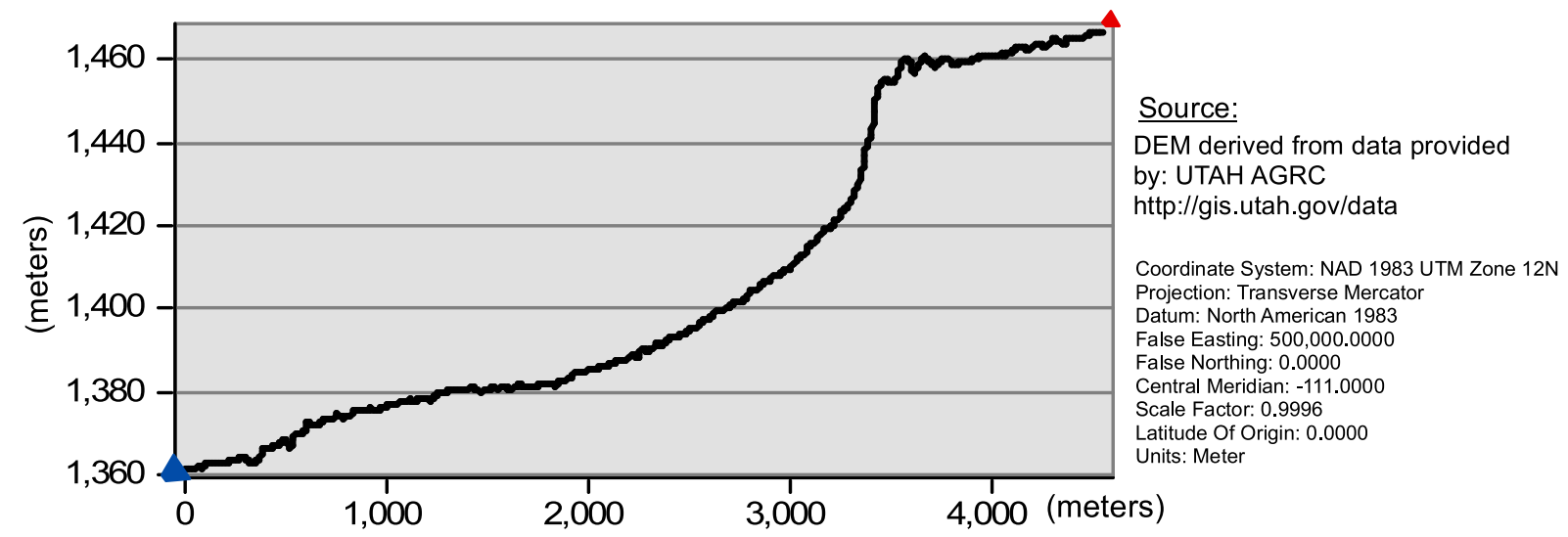

FIG. 1. (a) The location of the USU weather station and KVNU radio weather station overlaid upon the satellite street view and topographic contours (10-m interval). The inset map outlines Cache Valley and surroundings and the boundary of Cache County, Utah. (b) The cross-sectional profile between the two stations.

governed by radiative exchanges at the surface with depths of tens to hundreds of meters, and are much shallower than the regional subsidence inversions created by the development of high pressure ridges aloft. Air pollutants formed near the surface cannot diffuse through this local-regional combination of inversions that persist for some time and therefore accumulate over time. When these conditions persist for days, pollutants such as particulate matter of aerodynamic diameter $\leq$ $2.5 \mu \mathrm{m}\left(\mathrm{PM}_{2.5}\right)$ can and often do reach unhealthy levels. The health implications of such air quality are by no means minor as reported by Beard et al. (2012), who found that visits to the emergency department in Salt Lake City, Utah, from 2003 to 2008 had increased by $41 \%$ during what are referred to as persistent inversions (i.e., duration lasting $\geq 4$ days).

Located in northern Utah and southern Idaho, Cache Valley has a narrow geographic footprint with tall surrounding mountains (Fig. 1a). Because of its physiography and location, air quality during winter inversion days in Cache Valley oftentimes is the worst in the state and frequently is the worst in the nation (Malek et al. 2006; Silva et al. 2007; Wang et al. 2012). $\mathrm{PM}_{2.5}$ concentrations in Cache Valley are often elevated beyond 
the 24-h U.S. National Ambient Air Quality Standard (NAAQS) of $35 \mu \mathrm{g} \mathrm{m}^{-3}$, and the airshed ${ }^{1}$ was officially designated as nonattainment in 2009 (Environmental Protection Agency 2009). During persistent inversions, $\mathrm{PM}_{2.5}$ concentrations in Cache Valley commonly have exceeded those in the Salt Lake Valley, which is much larger in area, population, and pollutant source strength and is located about $120 \mathrm{~km}$ to the south (Gillies et al. 2010). Over 2001-13, winter $\mathrm{PM}_{2.5}$ concentrations in Cache Valley have exceeded the NAAQS for an average of $18 \pm 8$ days ( $95 \%$ confidence interval), subsequently increasing the risk of an inflammatory response in the residents' lung cells (Watterson et al. 2007) as well as having many other documented respiratory and cardiovascular health impacts (Brook et al. 2010; Beard et al. 2012; Correia et al. 2013).

Current estimates of future regional climate in this region suggest that the problem could become more prevalent. For example, climate-model simulations have suggested that the American West is likely to undergo an increased occurrence of circulation stagnation (i.e., stable high pressure conditions) that would increase the frequency of stagnant air masses over urban valleys and resultant degradation of air quality (Leung and Gustafson 2005; Horton et al. 2014). Few studies have examined the historical long-term changes of inversions in the interior West of the United States because of a lack of observations and inconsistent quality of station records. Among the few, Bailey et al. (2011) used radiosonde data to show that the frequency of upper-level inversions (such as capping inversions) in Salt Lake City has increased while the frequency of surface inversions (in the bottom $400 \mathrm{~m}$ ) has decreased. In Alaska, Bourne et al. (2010) reported that the frequency and depth of surface inversions have increased since the late 1980s, after a decrease from 1957. Nevertheless, these studies did not address the smaller-scale or local inversions that exist in narrow, populated valleys (such as Cache Valley) where upper-air sounding data are nonexistent and, as already noted, significant pollution episodes are of major concern.

Cache Valley offers a good case study of inversions and air-quality problems in an urban mountain valley that is experiencing rapid population growth. The current and future air-quality issues in Cache Valley will necessitate development of long-term planning and mitigation strategies (now obligatory because of nonattainment). These actions will require knowledge about the frequency of occurrence and intensity levels of inversions, and this raises a simple but key question: To

\footnotetext{
${ }^{1}$ An airshed is a part of the atmosphere that behaves in a coherent way with respect to the dispersion of emissions.
}

what extent has the inversion intensity and subsequent potential for increased $\mathrm{PM}_{2.5}$ concentrations changed historically? As was noted earlier, relevant critical information, that is, upper-air soundings that provide vertical profiles of temperature, is lacking.

Since the 1950s, general changes in the winter climate over Utah have resulted in a warming middle troposphere, an overall increase in surface air temperature, and accompanying reductions in both storm frequency and snow-to-rain ratio (Gillies et al. 2012). In northern Utah the increase in daily maximum air temperature was small, however, and in some valleys slight cooling trends were even present. Therefore, in northern Utah the combination of a midtropospheric warming and a neutral or cooling surface temperature would imply an enhancement of stable near-surface atmospheric conditions, that is, an increased intensity and/or frequency of occurrence of inversions with resultant implications on air quality in urban valleys. Hence, there is a need for a quantitative analysis regarding the climatological behavior for such localized valley inversions. Therefore, our goal was to document the inversion frequency and intensities in Cache Valley, as a classic case of a populated mountain valley, using only the available in situ weather-station measurements. We had five specific objectives:

1) to quantify changes in frequency of occurrence and intensity of inversions in Cache Valley over the last 57 years of record, using data from two local stations that cover a distinct elevation change,

2) to document the relationship between the frequency of occurrence and intensity of inversions and the mean value of surface air temperature (i.e., local climate),

3) building upon previous work (Gillies et al. 2012), to examine any connection of inversion-event intensity and frequency of occurrence with large-scale oceanic and atmospheric features associated with decadalscale oscillations in climate,

4) to consider the relationship between (i) inversion intensity, (ii) duration, and (iii) air temperature and measured values of $\mathrm{PM}_{2.5}$, and, if the results of objective 4 were significant enough,

5) to approximate the concentrations of $\mathrm{PM}_{2.5}$ during earlier periods on the basis of those results.

\section{Data sources}

Because atmospheric sounding data were not available for Cache Valley, a surrogate of inversions can be inferred using air temperature data from two nearby stations with an adequate difference in elevation. Years of observations have already shown that the interactions 
between surface snow-cover properties, net radiation, and surface skin temperature that produce strong inversions are reflected in the vertical temperature differences between such locations. After considerable searches and tests, we identified an optimal pair of Historical Climatology Network (HCN) weather stations in Cache Valley that are $98 \mathrm{~m}$ apart in elevation: 1) the Logan, Utah, KVNU radio station (station identifier USC00425182) on the eastern edge of the valley floor at $1362 \mathrm{~m}$ and 2) the Utah State University (USU) station (USC00425186) on the so-called east bench at $1460 \mathrm{~m}$ (Fig. 1a, left); their difference in elevation is identified in Fig. $1 \mathrm{~b}$ by a topographical cross section. The period of record was restricted to be from December 1956 through February 2013 on the basis of the available KVNU station data. The daily HCN station data were obtained online from the Utah Climate Center (http://climate.usu.edu).

It is important to note that USU and KVNU are the only pair of stations along the northern Wasatch Range with such a topographic relationship (i.e., between the valley floor and the "bench") that share a consistent longterm climate record with more than $95 \%$ data availability throughout the period of record, as defined in Moller and Gillies (2008). The HCN station at USU is the highest station in the valley that had a period of record commensurate with that of KNVU. As defined by the National Climatic Data Center, HCN stations are a "designated subset of the NOAA Cooperative Observer Program (COOP) Network ... selected according to their spatial coverage, record length, data completeness, and historical stability" and consist "primarily of long-term COOP stations whose monthly temperature records have been adjusted for systematic, nonclimatic changes that bias temperature trends" (http://www.ncdc.noaa.gov/oa/ climate/research/ushcn/). Station history, including movement, sensor updates, and so on, can be found online (http://www.ncdc.noaa.gov/homr/). ${ }^{2}$ For the evaluation of possible land-use changes, the Utah Automated Geographic Reference Center (http://gis.utah.gov) provides aerial photography from the mid-1990s to 2012. The MultiResolution Land Characteristics Consortium provides a National Land Cover Database online (http://www.mrlc. gov). As is shown in the online supplemental material, the surrounding areas that encompass the USU and KVNU stations have undergone only very limited development within the study period.

\footnotetext{
${ }^{2}$ Additional station information for the USU station is provided at http://weather.usu.edu/htm. Temperature data at this station are replicated; two thermistors and a platinum resistance thermometer are used, and a comparison check is performed on a weekly basis. The sensor specifications can be found at http://weather.usu.edu/ $\mathrm{htm} /$ specifications.
}

For air-quality data, we utilized the 12-yr record of 24-h $\mathrm{PM}_{2.5}$ collected at a location in downtown Logan (southern part of Cache Valley and near the KVNU site) for the winters of 2001-12, obtained from the Utah Division of Air Quality Monitoring Center PM2.5 data archive in February of 2013 (http://www.airmonitoring. utah.gov/dataarchive/archpm25.htm; Martin 2006). Monthly climate indices were also analyzed, and these were obtained from NOAA's Earth System Research Laboratory (ESRL; http://www.esrl.noaa.gov/psd/data/climateindices/). The NCEP-NCAR reanalysis data (Kalnay et al. 1996) provided by ESRL were also used. Upper-air data were estimated using the Salt Lake City International Airport soundings (KSLC).

\section{Results}

\section{a. Changes in the inversion frequency and intensity}

We compared the daily maximum temperature $T_{\max }$ between the two stations for each winter season (1 December-28 February). The daily $T_{\max }$ values were used to depict winter inversions because they are the most sensitive to persistent inversion conditions, as well as to prevent confusion with routine nocturnal radiative inversions that would be reflected in the daily minimum temperature $T_{\min }$. The difference in $T_{\max }$ of each day (USU minus KVNU) $\Delta T$, referred to as inversion intensity, is plotted in Fig. 2a for each winter from 1956 to 2012. The box size indicates the data interquartile range (IQR), and the centerline represents the median. There is a pronounced reduction in the $\Delta T$ range after the 1980s as evidenced by the decline in the IQR. Expressed quantitatively, by using 1985 as a midpoint, the mean variance of $\Delta T$ prior to 1985 was $7.7^{\circ} \mathrm{C}$, but it was reduced to $3.5^{\circ} \mathrm{C}$ after 1985 . We then computed the inversion frequency by classifying an inversion as being when the daily $T_{\max }$ at the USU station was greater than that of the KVNU station (i.e., $\Delta T$ above the zero line in Fig. 2a); it is shown in Fig. 2b. As is indicated by the 7-yr running mean, the inversion frequency increased by about $20 \%$ starting in the 1980 s and progressing into the early 1990s, after which it subsequently decreased by approximately $30 \%$ through 2012 . For verification purposes, we also plotted the number of days with missing data in Fig. $2 b$ (i.e., either one or both stations had a missing record). It is feasible that the increase in missing days during the late 1990s might have contributed to the apparent decrease in inversion frequency, but such a circumstance cannot explain the large frequency reduction from the late 1980s to the turn of the century.

The relationship between inversion intensity and the air temperature between the two stations was examined 
(a)

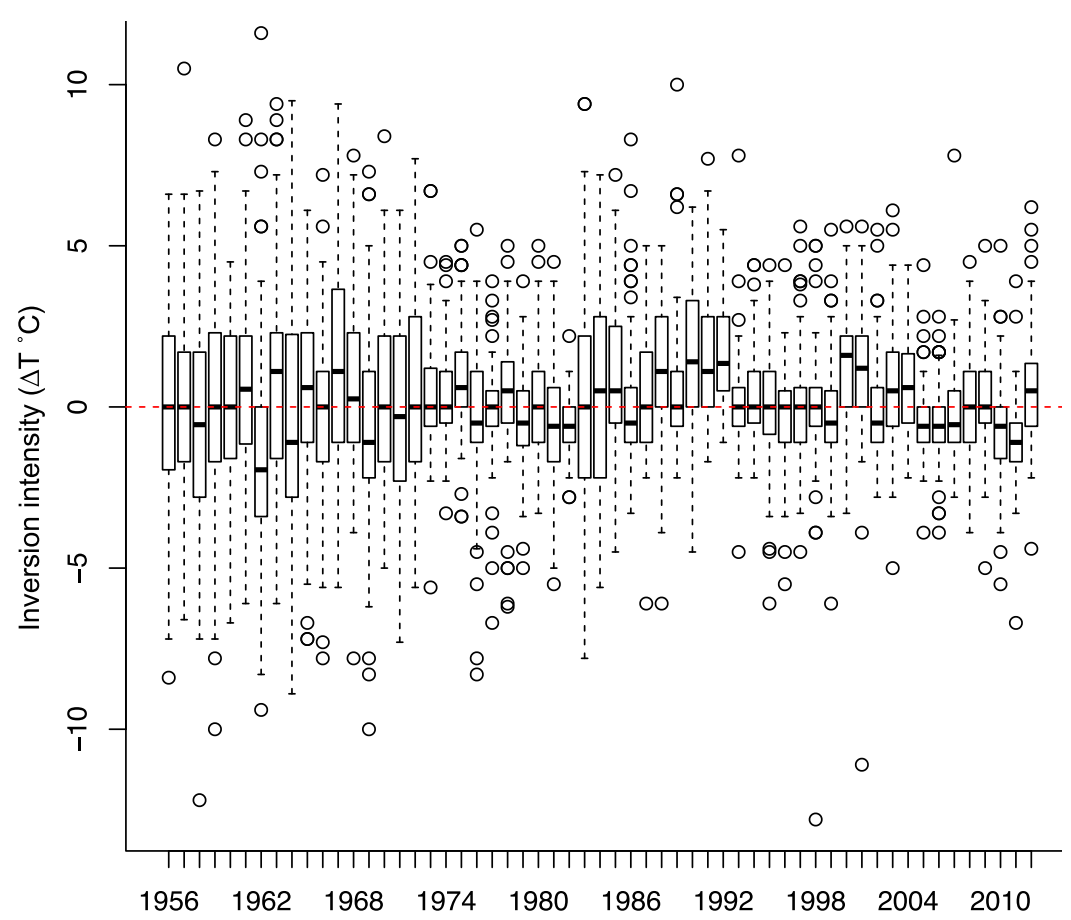

(b)

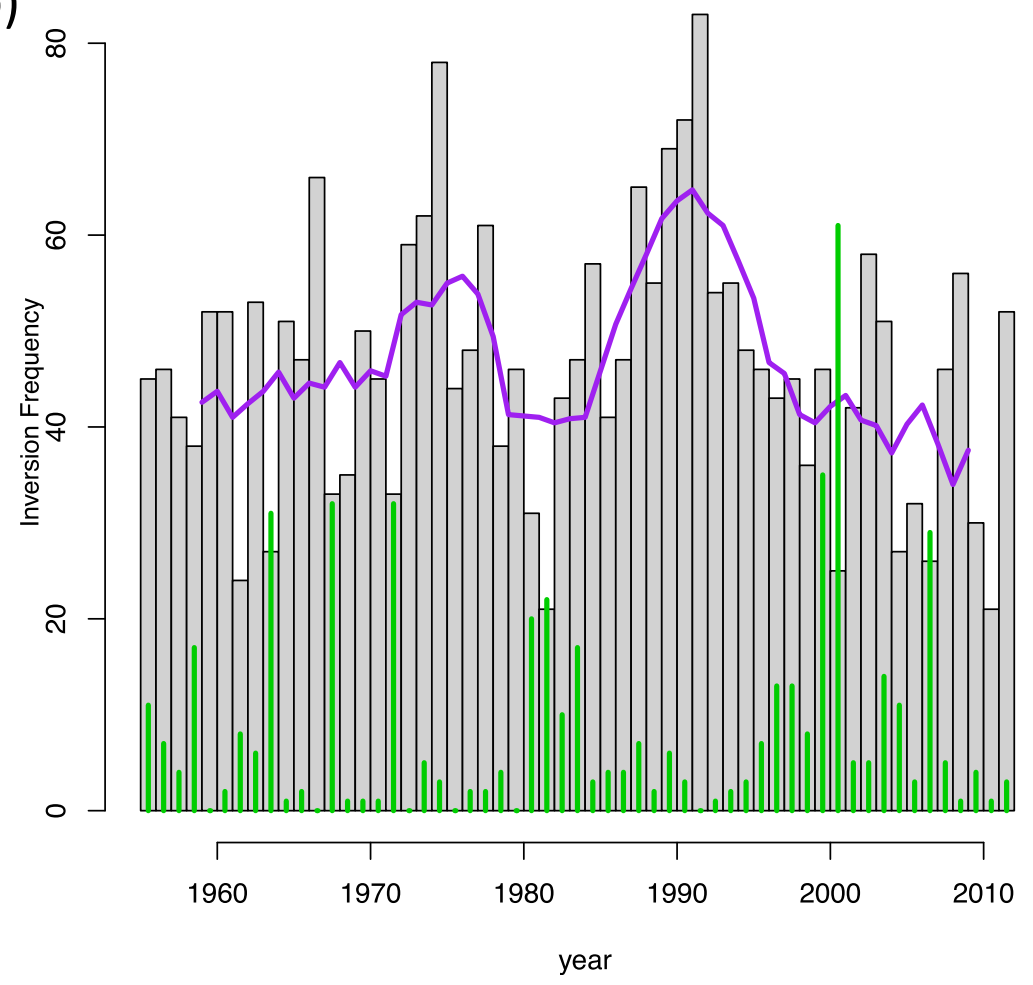

FIG. 2. (a) Daily $T_{\max }$ differences between the USU and KVNU stations $\left(\Delta T ;{ }^{\circ} \mathrm{C}\right)$ during each December-February season from 1956 to 2012 (box plot). The box outline shows the interquartile range: the third quartile minus the first quartile. The black center line represents the data median. Data beyond the IQR but within $1.5 \times$ IQR are indicated by the length of the whisker. Extreme data beyond $1.5 \times$ IQR are represented by circles. (b) The number of inversion days (gray histogram) for each winter season, and its 7-yr running mean (purple line). The number of missing days at either of the stations is given by the green bars. 
Daily mean temperature range for each level $\left({ }^{\circ} \mathrm{C}\right)$

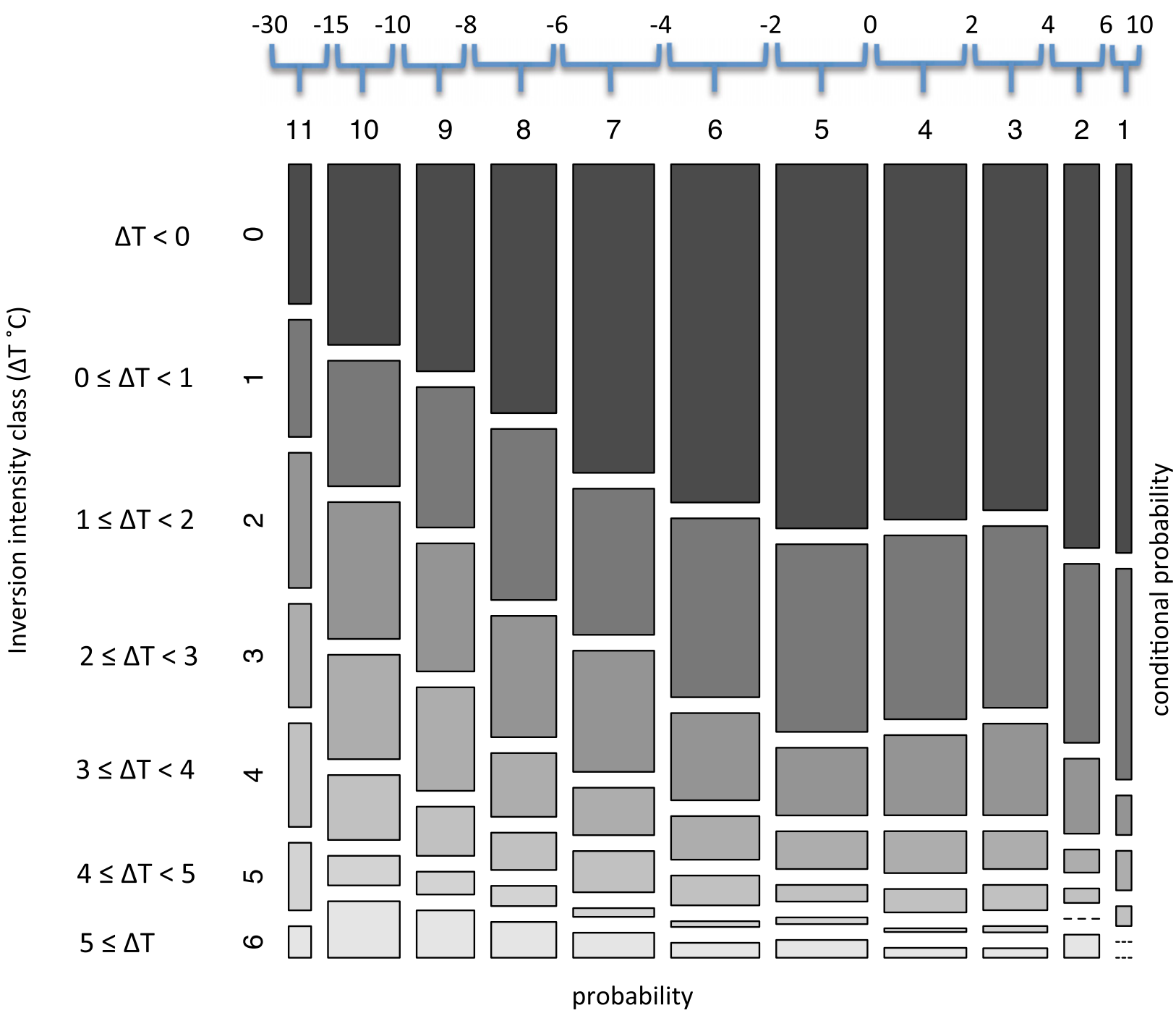

FIG. 3. A mosaic plot of inversion intensity and daily mean air temperature. The daily mean air temperature is categorized into 11 levels ( $x$ axis) from cold (level11) to warm (level1). The width of the bins indicates the probability associated with each level. Inversion intensity $\Delta T$ ( $y$ axis) is broken down into seven classes. Class 0 represents no inversion events (i.e., $\Delta T<0$ ), class 1 represents $\Delta T \geq 0^{\circ} \mathrm{C}$ but $<1^{\circ} \mathrm{C}$, and so forth. Each bar in a bin indicates the conditional probability of each inversion-intensity class at the given daily mean air temperature level.

because the chemistry involved in forming $\mathrm{PM}_{2.5}$ is related to the air temperature; that is, ammonium nitrate particulate formation becomes more favorable as air temperatures decline (Mozurkewich 1993). We categorized inversion intensity into seven classes on the basis of the magnitude of $\Delta T$. These seven classes (0-6) are shown along the left-hand side of the $y$ axis of the mosaic plot $^{3}$ in Fig. 3. When inversion intensity was negative, it

\footnotetext{
${ }^{3}$ A mosaic plot is a graphical method for visualizing data from two or more variables.
}

was categorized as inversion-intensity class 0 and is representative of the absence of inversion conditions. If inversion intensity was zero or positive but less than $1^{\circ} \mathrm{C}$, the intensity was categorized as inversion-intensity class 1 , and so on up to the highest class $6\left(\Delta T \geq 5^{\circ} \mathrm{C}\right)$ of inversion intensity. To consider the effects of air temperature, we computed the daily mean air temperature $\bar{T}_{\text {usu/knvu }}$ as $\left(\bar{T}_{\text {usu }}+\bar{T}_{\text {knvu }}\right) / 2$, where $\bar{T}$ at either of the two stations was computed as $\left(\bar{T}_{\max }+\bar{T}_{\min }\right) / 2$. We then categorized $\bar{T}_{\text {usu/knvu }}$ as follows: if $\bar{T}_{\text {usu/knvu }}$ lay between $6^{\circ}$ and $10^{\circ} \mathrm{C}$, the category assigned was level 1 , and so on through $\bar{T}_{\text {usu/knvu }}$ between $-30^{\circ}$ and $-15^{\circ} \mathrm{C}$ (categorized 
as level 11), as marked in the figure. In addition, the width of the vertical bars (lower $x$ axis) represents the probability of that daily mean air range falling within each level. For example, the probability of experiencing winter temperatures in Cache Valley that fall within levels 1,2 , or 11 (i.e., between $4^{\circ}$ and $10^{\circ} \mathrm{C}$ or between $-30^{\circ}$ and $-15^{\circ} \mathrm{C}$ ) is relatively low (i.e., denoted by the thinnest vertical bars), whereas at all other levels the probabilities are distinctly higher. In essence then, climatological "extreme" temperature conditions are possible but not likely. An additional aspect of the mosaic-plot analysis was to split each vertical bar into discrete horizontal segments that are proportional to the conditional probabilities (right-hand side) of the inversion-intensity classes, that is, to indicate the probability of each inversion-intensity class at each temperature level. For example, at level 11, when the daily mean air temperature experienced was extremely cold (from $-30^{\circ}$ to $-15^{\circ} \mathrm{C}$ ), the chance of not having an inversion event is small (i.e., the uppermost split has a probability of 0.2 , or $20 \%$ of the time no inversion occurred within that temperature range).

As shown in the mosaic plot, the inversion intensity is strongly connected to the daily mean air temperature. A question is raised, however, about the impact of snow cover, because the presence and extent of snow coverage are known to deepen inversion intensity. It would appear that snow cover does not play as significant of a role as one might at first expect in deepening inversion intensity in Cache Valley-at least over the time period analyzed here. The evidence for the prior statement lies in the fact that the conditional probabilities (i.e., the widths) at each class vary little from warm winter-season conditions (in which any snow cover that exists tends not to persist) to those that are cold where snow cover endures; we present further statistical evidence to this effect later in the paper. For the time being and because COOP stations do not record snow coverage but only snow depth, we used the snow depth as a proxy to infer snow coverage over Cache Valley. Although the two stations lacked consistent long-term records of snow-depth data for the study period (i.e., about $40 \%$ of the data were missing), observations and anecdotal experience indicated that widespread snow was on the ground for an average two-thirds of the winter seasons. We do realize, however, that when air temperatures were very cold our definition of inversion intensity might not capture deeper inversions, because inversion intensity as defined by $\Delta T$ is constrained to apply over $98 \mathrm{~m}$, and to examine such a circumstance would require additional sensor(s) at higher elevations on the mountain slopes that were unavailable.
Figure 4 shows the inversion intensities for the entire 57-yr period at all temperature levels. Level 11 (Fig. 4a), reflecting the leftmost vertical bin of Fig. 3, is of particular interest because it clearly exhibits two marked features. The first occurs early in the record (i.e., prior to 1980), during which temperatures of level-11 magnitude did not necessarily lead to the occurrence of an inversion; this result is in concurrence with the $20 \%$ conditional probability of not having an inversion event at level 11 (see leftmost bar in Fig. 3). Around 1980, however, the situation changed, whereupon an upward trend in inversion intensities to lie above zero is observed; this situation means that, from 1980 onward, when level-11 temperatures were established then inversions were assured, albeit of varying intensities. Similar patterns and shifts were also found to differing degrees at levels 10 and 9 (Figs. 4b,c). At level 8 and levels below 8 (Figs. $4 \mathrm{~d}-\mathrm{h}$ ) the inversion intensities do not exhibit any of the tendencies that are evident at levels 9-11.

Given the limitation of having only two reliable stations to depict the change in inversion characteristics, the variations revealed in Figs. 2-4 may reflect not only inversion occurrences and intensities but the inversion depth as well; that is, Cache Valley inversions might have become shallower after 1990. As was noted before, however, it was not possible to adequately address the issue of inversion depth because of the lack of additional temperature sites at differing elevations.

\section{b. Interdecadal climatic oscillation}

Gillies et al. (2012) reported upon a distinct warming in northern Utah that has occurred since the 1950s both at and above $700 \mathrm{hPa}$ and stated that this warming was associated with an anomalous anticyclone extending to eastern Canada. In addition, a recent study by Wang et al. (2014) found that the North Atlantic Oscillation (NAO) appears to modulate inversion intensities and timing in northern Utah, both of which exhibit a quasi6-yr cycle. A smoothed plot (i.e., using a 7-yr running mean) of the winter NAO index (Fig. 5a, red line) is in general alignment with the low-frequency fluctuation of the inversion intensity (blue line). The pronounced increase in inversion intensity during the 1980s is apparent and aligns closely with the phase reversal (from negative to positive) of the decadal variation of the NAO (Hurrell 1995). Figure 5b shows the correlation between $\Delta T$ and NAO for each temperature level: levels 9-11 (i.e., those particularly cold days that were identified previously) exhibit significant correlation coefficients (significance level $p<0.05$ ). The mechanisms through which large-scale circulation patterns are induced by the $\mathrm{NAO}$ and affect inversion intensities in northern Utah 

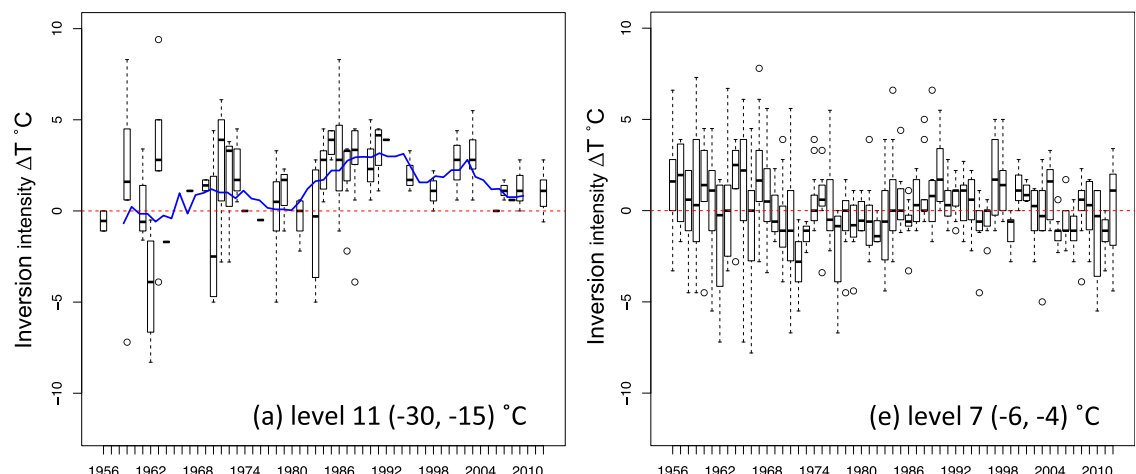

$\begin{array}{lllllllllll}1956 & 1962 & 1968 & 1974 & 1980 & 1986 & 1992 & 1998 & 2004 & 2010\end{array}$

$\begin{array}{lllllllllll}1956 & 1962 & 1968 & 1974 & 1980 & 1986 & 1992 & 1998 & 2004 & 2010\end{array}$
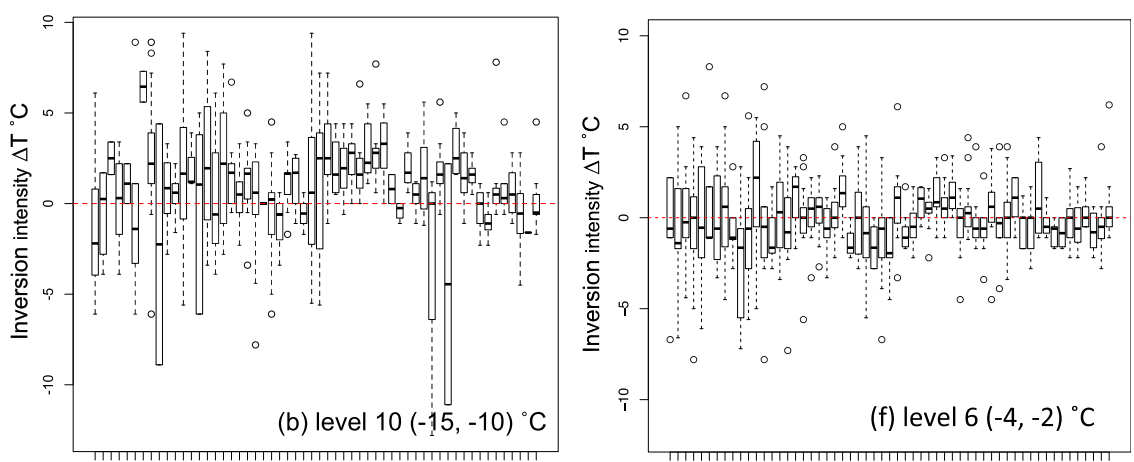

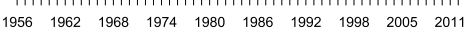

$\begin{array}{llllllllll}1956 & 1962 & 1968 & 1974 & 1980 & 1986 & 1992 & 1998 & 2004 & 2010\end{array}$
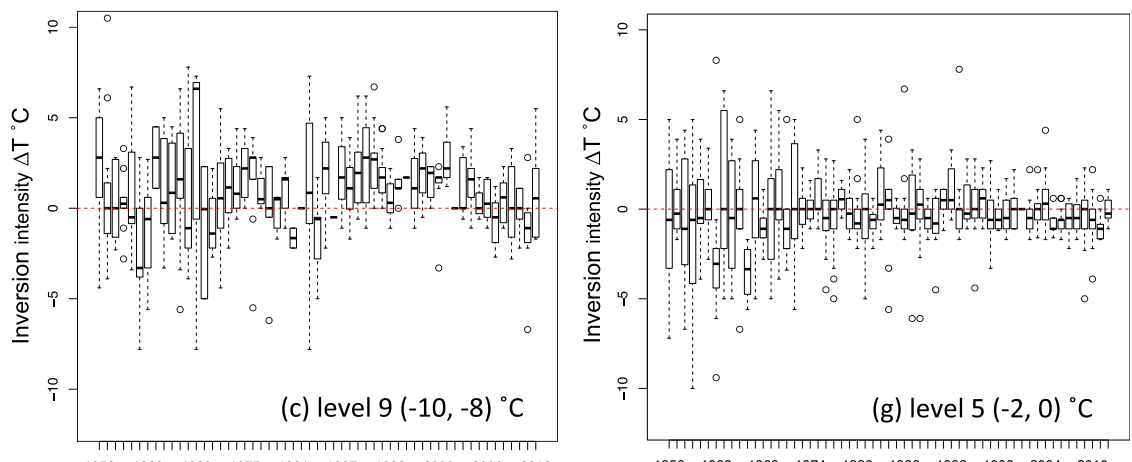

$\begin{array}{llllllllllllll}1956 & 1963 & 1969 & 1975 & 1981 & 1987 & 1993 & 2000 & 2006 & 2012\end{array}$
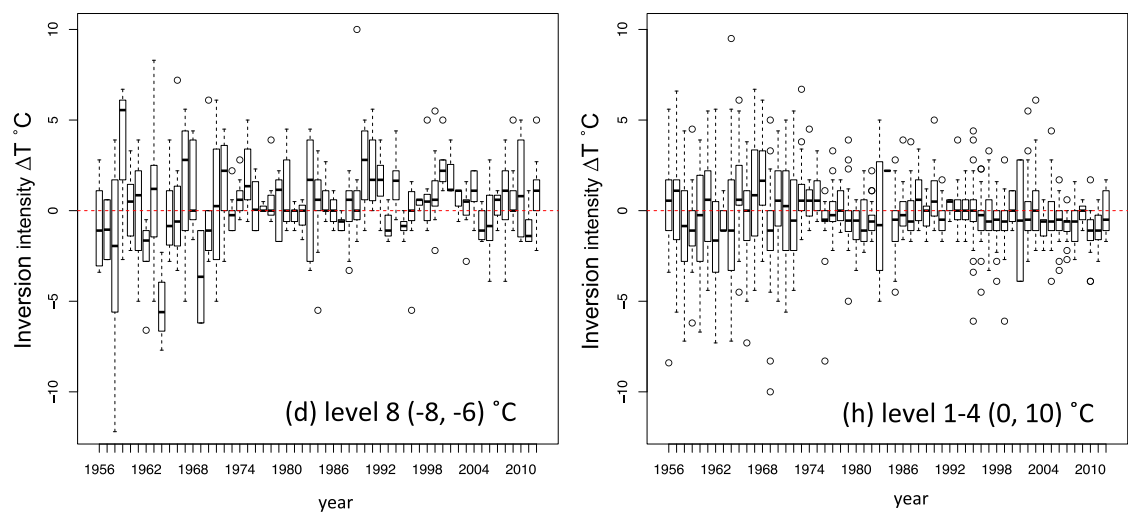

FIG. 4. As in Fig. 2a, but for $\Delta T$ at air temperature levels from (a) 11 to (g) 5. (h) Temperature levels from 1 to 4 are combined. The blue line in (a) indicates the $7-y r$ running mean. The range of $(-30,-15)$ in (a) indicates values $\geq-30^{\circ} \mathrm{C}$ and $<-15^{\circ} \mathrm{C}$, and so forth for the rest of the levels. 

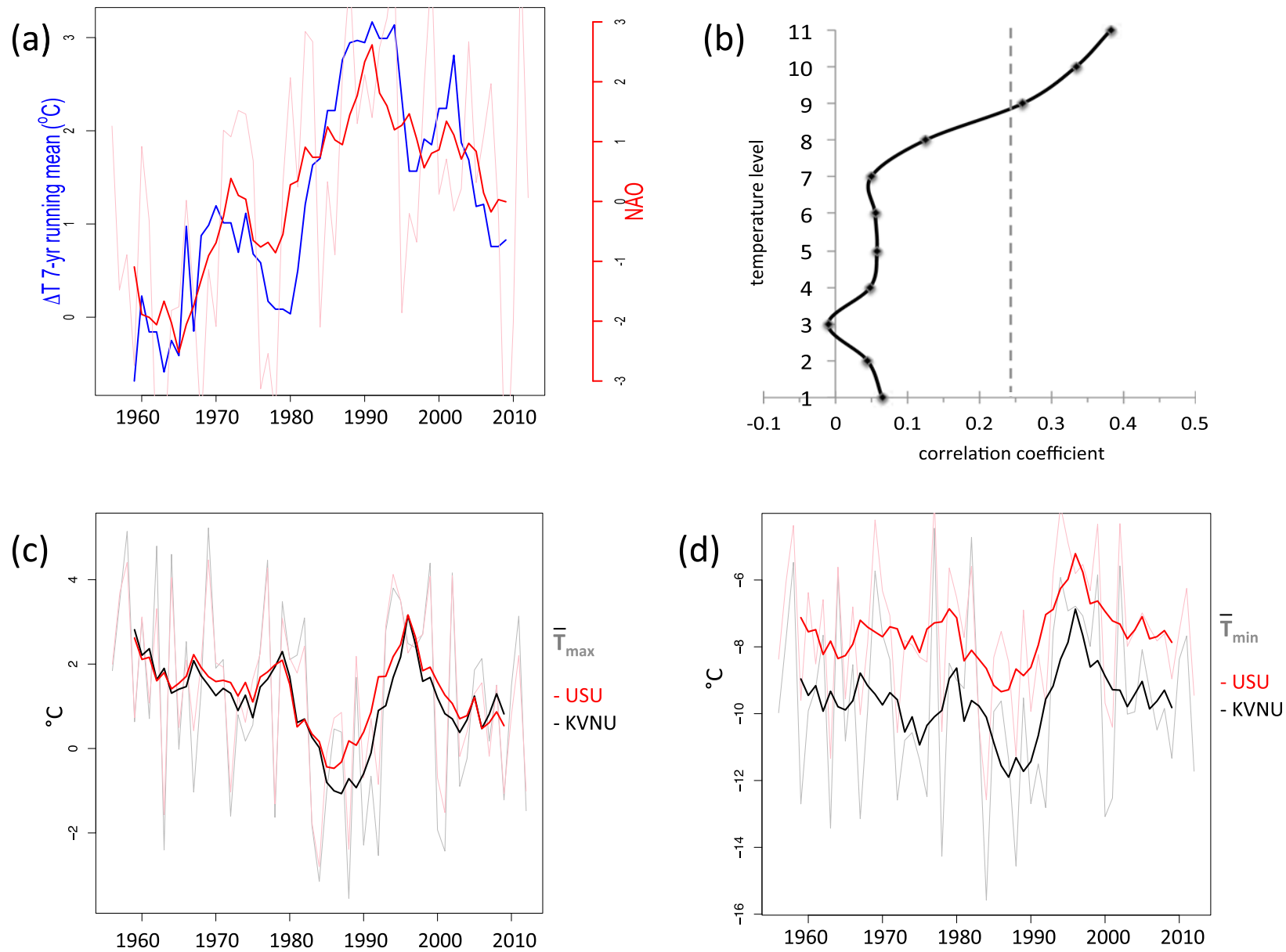

FIG. 5. (a) The NAO (pink thin line) overlaid with its 7-yr running mean (red line) in comparison with the 7-yr running mean of $\Delta T$ from temperature level 11 in Fig. 4a (blue line). (b) Correlation coefficients between the raw NAO and $\Delta T$ values at all 11 levels; the vertical dashed line indicates the $95 \%$ significance level. (c) Winter-mean daily maximum temperature and its 7-yr running mean at the USU (red) and KVNU (black) stations. (d) As in (c), but for daily minimum temperature.

were examined recently by Wang et al. (2014). The interdecadal association between the NAO and coldday inversions, as illustrated by levels 9-11, is intriguing and is certainly worthy of further investigation.

The 7-yr running means of $T_{\max }$ for both stations (Fig. 5c) are coherent and are in synchronous oscillation but indicate an overall cooling trend that is statistically significant ( $p \leq 0.01$ ). Of interest is that this is in contrast to the widespread surface warming observed throughout Utah (Gillies et al. 2012). Meanwhile, neither station exhibits a long-term trend in $T_{\min }$ (Fig. $5 \mathrm{~d} ; p$ values of Mann-Kendall trend test for $T_{\min }$ at both stations $\geq$ $0.25)$. A pronounced cooling episode in both $T_{\max }$ and $T_{\min }$ occurred between the $1980 \mathrm{~s}$ and $1990 \mathrm{~s}$ and coincides with phase reversal in the $\mathrm{NAO}$; it was coincidentally accompanied by a distinct and substantial increase in the cold-day inversion intensity (see Fig. 5a). In addition, the near-surface cooling corresponds to the peak inversion frequency in the late 1990s (Fig. 2b). As was pointed out in section 2 and the online supplemental material, any change in temperatures over time for the period in question is not considered to be attributable to land-use change. Instead, the likely driver seems to be large-scale climate via the NAO (see Fig. 5a), the influence of which on stagnant high pressure patterns is further documented in Wang et al. (2014).

\section{c. Shedding some light on $P M_{2.5}$ variations prior to 2001}

Because winter inversions in Cache Valley are inextricably linked to degradation in air quality, we investigated the relationship between inversion intensity and $\mathrm{PM}_{2.5}$ concentrations. First, we divided the $\mathrm{PM}_{2.5}$ level into four groups as per U.S. Environmental Protection Agency (EPA) protocols for calculating air quality indices in which ambient pollutant concentrations 


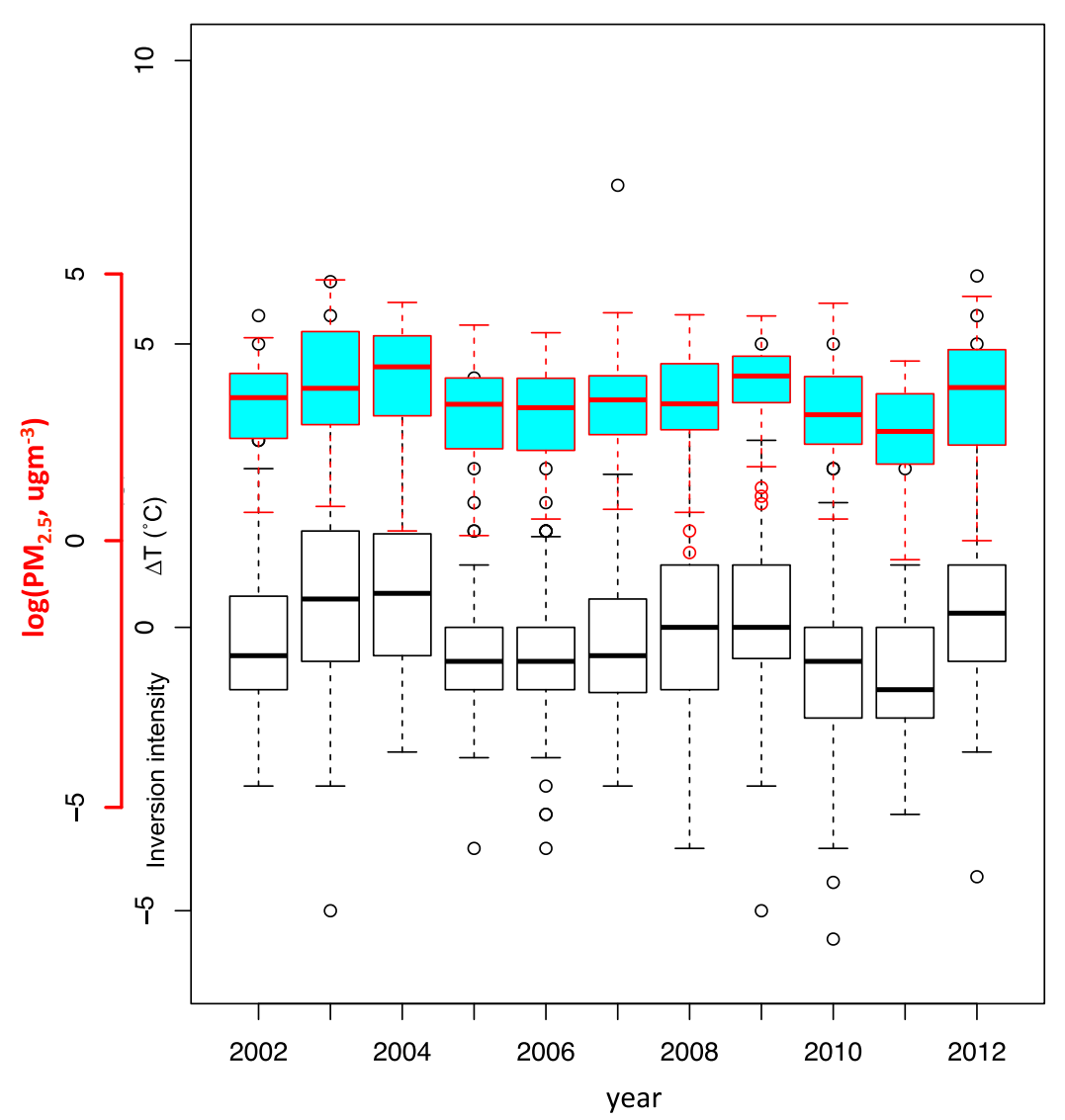

FIG. 6. Values of $\Delta T$ (black) and log-transformed $\mathrm{PM}_{2.5}$ values (blue) at each winter season.

The box-plot features are the same as Fig. 2a.

are grouped into discrete ranges on the basis of potential health impacts. The $\mathrm{PM}_{2.5}$ discrete groups ${ }^{4}$ were 1) less than $25.5 \mu \mathrm{g} \mathrm{m}^{-3}, 2$ ) at least 25.5 but less than $35.5 \mu \mathrm{g} \mathrm{m}^{-3}, 3$ ) at least 35.5 but less than $65.5 \mu \mathrm{g} \mathrm{m}^{-3}$, and 4) at least $65.5 \mu \mathrm{g} \mathrm{m}^{-3}$. To reduce skewedness in the data, the $\mathrm{PM}_{2.5}$ levels were transformed to logarithmic coordinates $\left[\log \left(\mathrm{PM}_{2.5}\right)\right]$. In Fig. 6, we compare the distributions of $\Delta T$ and $\log \left(\mathrm{PM}_{2.5}\right)$. The fluctuations in the median of $\Delta T$ and $\log \left(\mathrm{PM}_{2.5}\right)$ are similar over the past 11 years.

Next, we regressed $\log \left(\mathrm{PM}_{2.5}\right)$ upon five parameters: 1) $\Delta T, 2)$ the daily mean air temperature of the two stations, 3) the inversion duration (i.e., a count of how many consecutive days in a row on which an inversion event was observed), 4) snow cover at the USU station (yes $=1$; no $=0$ ), and 5 ) snow cover at the KVNU station. First we performed model diagnostics to

\footnotetext{
${ }^{4}$ Note that $65 \mu \mathrm{g} \mathrm{m}^{-3}$ was the pre-2006 $\mathrm{PM}_{2.5}$ 24-h standard (the current standard is $35 \mu \mathrm{g} \mathrm{m}^{-3}$ ).
}

determine whether the inclusion of snow cover as a parameter (parameters 1-4 or 1-5) was important when compared with the model with only temperature properties (parameters 1-3). The results verified what was found previously; that is, they did not yield any significant difference, indicating once again that snow cover only acts as a modulating factor rather than a determining one in Cache Valley inversion development. An alternate explanation could be that any snow-cover impact was already accounted for in those temperature properties (inversion intensity, duration, etc.). Nevertheless, a temperature-based regression model was constructed for $\log \left(\mathrm{PM}_{2.5}\right)$ in which the coefficients for parameters 1,2 , and 3 were $0.096,-0.085$, and 0.075 , respectively, and the intercept was 2.18 , yielding the equation

$$
\begin{aligned}
\log \left(\mathrm{PM}_{2.5}\right)= & 2.18+0.096(\text { parameter } 1) \\
& -0.085(\text { parameter } 2) \\
& +0.075(\text { parameter } 3)
\end{aligned}
$$


(a)

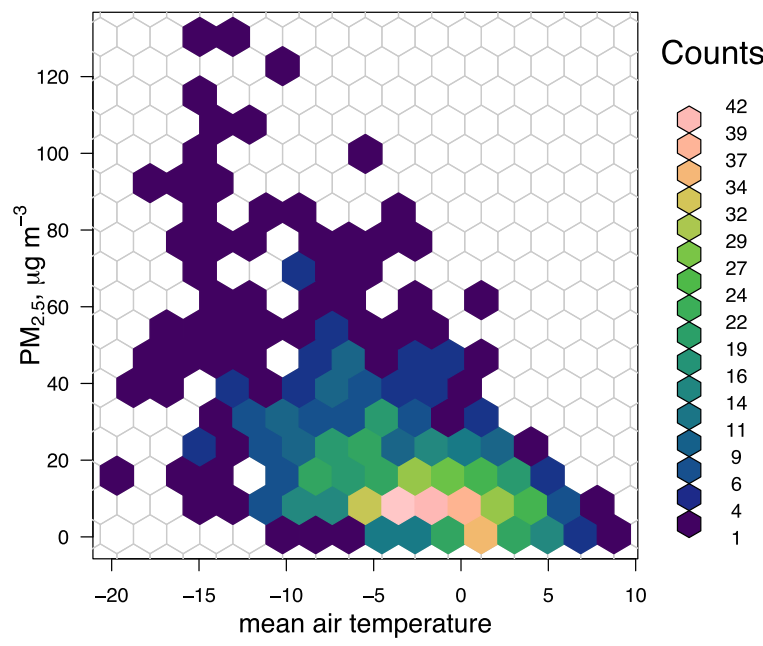

(b)

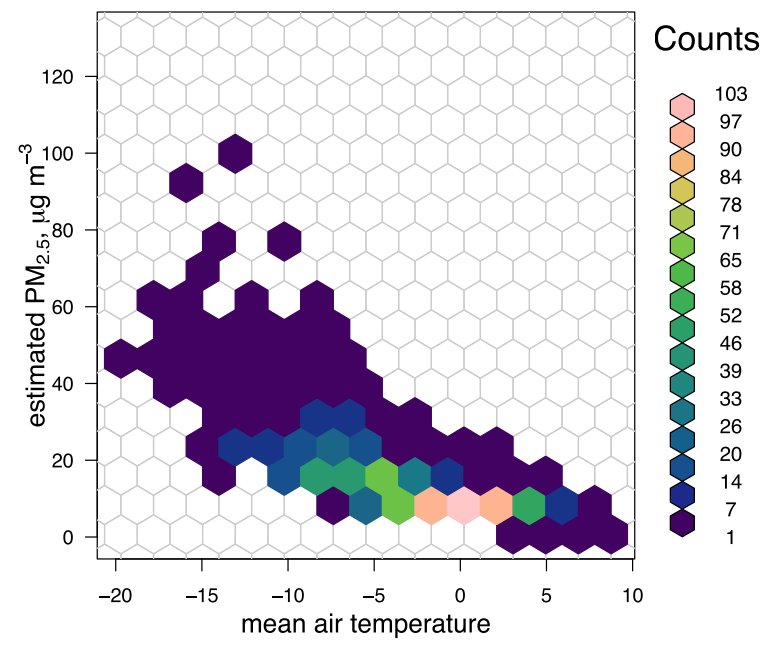

FIG. 7. The comparison of (a) observed $\mathrm{PM}_{2.5}$ and (b) model-fitted $\mathrm{PM}_{2.5}$ values as based upon meteorological conditions, plotted as the frequency of counts as indicated by the color scale to the right.

All of the coefficients were significant with a $p$ value of less than 0.001 , and the adjusted $R^{2}$ (where $R$ is correlation coefficient) for the model was 0.38 . We were therefore able to estimate the $\log \left(\mathrm{PM}_{2.5}\right)$ values prior to 2001 and convert them back to a normal scale.

The comparison of the observed concentration levels with the model-fitted (i.e., estimated) $\mathrm{PM}_{2.5}$ levels is presented in Fig. 7 as a distribution of density of counts. Because $\mathrm{PM}_{2.5}$ is a product of combusted chemistry that may not exhibit a linear relationship with all predictor variables (Mozurkewich 1993), the model was unable to capture the total variability of the response and so has a tendency to underestimate the extreme levels. The purpose of this regression model is not for prediction per se but to shed some light on the impact of daily mean temperature conditions on $\mathrm{PM}_{2.5}$ prior to 2001, when air-quality data were unavailable. In this regard, the modeled $\mathrm{PM}_{2.5}$ can provide a conservative estimate for past levels of $\mathrm{PM}_{2.5}$ as a function of climate variability.

The observed and estimated $\log \left(\mathrm{PM}_{2.5}\right)$ values are plotted in Fig. 8 for temperature levels 6-11. At levels 10 and 11 (Figs. 8a,b), the model estimate of $\log \left(\mathrm{PM}_{2.5}\right)$ suggests that on particularly cold days there would have been significant pollution episodes. In addition, the model captures the upward trend during the 1986-91 period, which coincides with the observed increase in the inversion frequency and $\Delta T$ described previously (Figs. 2b, 4a). At level 9, the upward trend and likely pollution episodes are likewise captured. At levels 6-8, the modeled response of $\log \left(\mathrm{PM}_{2.5}\right)$ was depressed, suggesting few intense pollution episodes; this result seems unrealistic given recent observations and is conceivably indicative of the role/limitation of not being able to include combusted chemistry in the statistical model. Nevertheless, one can take note that a bias exists, that is, that the modeled $\log \left(\mathrm{PM}_{2.5}\right)$ is underestimating the $\mathrm{PM}_{2.5}$ concentrations prior to 2001 .

\section{Summary, conclusions, and discussion}

Inversions in Cache Valley are difficult to characterize historically because of the absence of upper-air measurements. A practical approach (i.e., differences in $T_{\max }$ between the stations were used as a surrogate for shallow inversions) was applied that utilized a long and consistent historical air temperature measurement set from two stations at distinctly different elevations; the existence of such a data pairing is rare along the Wasatch metropolitan area of northern Utah. Two HCN stations that were $4.5 \mathrm{~km}$ apart with a difference in elevation of about $100 \mathrm{~m}$ were used for the period of 1956-2012. Using appropriate statistical techniques, the analyses presented here offer some insights into the interesting nature of inversion dynamics in an urban-growth region of Utah. Our initial analysis revealed that there was no clear long-term trend found in the inversion intensity $\Delta T$ over the length of the record but that there was a pronounced reduction in the $\Delta T$ range after the 1980s. The 

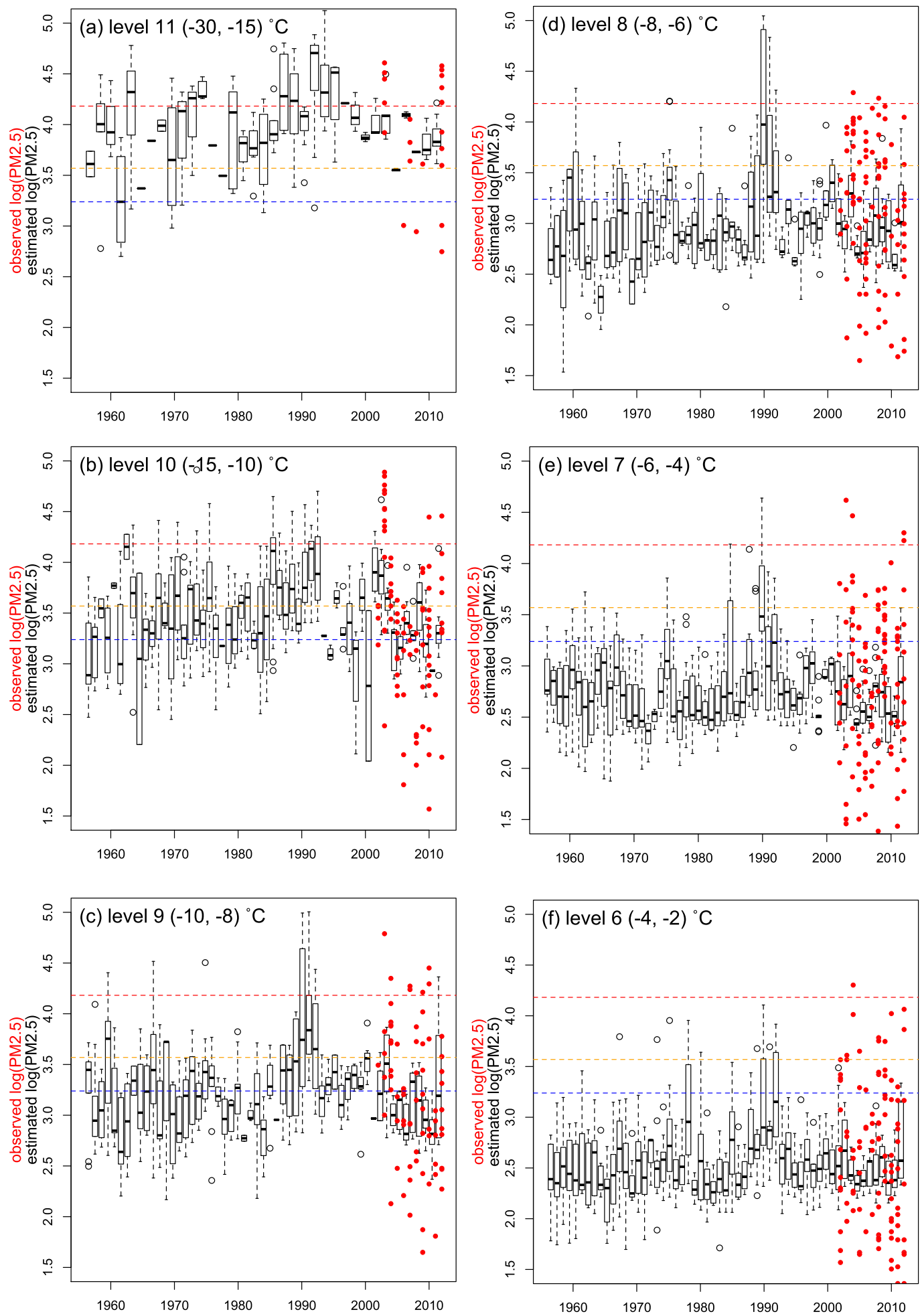

FIG. 8. Comparison of the log-transformed observed $\mathrm{PM}_{2.5}$ (red dots) and model-fitted $\mathrm{PM}_{2.5}$ values (box plots) as based upon meteorological conditions at air temperature class levels from (a) 11 to (f) 6 . The dashed horizontal lines represent the NAAQS levels of $\mathrm{PM}_{2.5}: 25.5$ (blue), 35.5 (yellow), and 65.5 (red) $\mu \mathrm{g} \mathrm{m}^{-3}$. 
inversion frequency did increase markedly starting in the early 1980s and extending into the early 1990s, at which point the trend reversed. The daily mean air temperatures were categorized with $\Delta T$ within a mosaic plot, and the results indicated that during cold days (daily mean air temperature of less than $-8^{\circ} \mathrm{C}$ ) the chance of an inversion developing has increased considerably since 1990 . Most notable is that when the daily mean air temperature value was below $-15^{\circ} \mathrm{C}$ an inversion was assured. Moreover and of interest, snow cover did not play a particularly substantive part in inversion development as one would expect. In fact, evidence was presented to the effect that the inversion intensity and frequency in the 1980s were accompanied by a surface cooling; such changes (of inversions on cold days) were aligned with the phase reversal of the NAO's interdecadal variation. Last, a regression model was developed to simulate $\mathrm{PM}_{2.5}$ concentrations for the years prior to 2001. Although the model underestimated extreme $\mathrm{PM}_{2.5}$ concentrations, the results implied increasing $\mathrm{PM}_{2.5}$ levels through the 1980s that declined to some degree after 1990; these are observed to differing extents in varying temperature regimes. It is important to note once again that the statistical model presented here is simply a function of temperature and did not include chemical kinetics, which is arguably a big factor in Cache Valley in inversion dynamics (Malek et al. 2006; Martin 2006).

The interior West including Utah has experienced a widespread warming in the winter season, and this regional warming is projected to continue through the coming century (e.g., Gillies et al. 2012; Peacock 2012). By contrast, Cache Valley has shown a cooling trend in $T_{\max }$ and a slight change in $T_{\min }$; this situation is an anomaly relative to the statewide temperature trends over the 1950-2010 period. Such an inverse tendency of the local surface temperatures in the valley might suggest that the observed intensification of high pressures over the northern Rocky Mountains promotes radiative cooling that acts to enhance surface inversions and to cool the air temperatures in the narrow valley. Given the near-1500-m elevation of Cache Valley, the observed change in the inversion frequency during cold days may have kept the mountain valley from experiencing the regional surface warming. Such a possibility presents an interesting case for the interaction or contrast between regional climatic warming and differing responses at local scales.

Our results suggest that alternative methods are possible in the estimation of decadal-scale changes in the frequency and intensity of inversions in mountain valleys of the interior American West when upper-air sounding data are nonexistent and/or snow-cover data are unavailable. It has been shown that in Cache Valley there are coherent temporal patterns in inversions that are associated with decadal-scale climate trends associated with the NAO. Other valley locations in the region could be examined for which HCN data exist at similar elevation differences and have a consistent and prolonged period of record. In light of current and ongoing air-quality discussions in the state of Utah, it is important to research the frequency and intensities of inversions and associated pollution episodes by all means possible, because safeguarding good air quality is essential for public health, the economy, and quality of life.

Acknowledgments. Data-processing assistance and valuable comments provided by Martin Schroeder and Robert Davies are highly appreciated. We thank Ben Crabb for his assistance on spatial data processing. The recommendations of anonymous reviewers enhanced our paper considerably. This study was supported by the Utah Agricultural Experiment Station, Utah State University (No. 8624), and Bureau of Reclamation WaterSMART Grant R13AC80039.

\section{REFERENCES}

Bailey, A., T. N. Chase, J. J. Cassano, and D. Noone, 2011: Changing temperature inversion characteristics in the U.S. Southwest and relationships to large-scale atmospheric circulation. J. Appl. Meteor. Climatol., 50, 1307-1323, doi:10.1175/2011JAMC2584.1.

Beard, J. D., C. Beck, R. Graham, S. C. Packham, M. Traphagan, R. T. Giles, and J. G. Morgan, 2012: Winter temperature inversions and emergency department visits for asthma in Salt Lake County, Utah, 2003-2008. Environ. Health Perspect., 120, 1385, doi:10.1289/ehp.1104349.

Bourne, S. M., U. S. Bhatt, J. Zhang, and R. Thoman, 2010: Surface-based temperature inversions in Alaska from a climate perspective. Atmos. Res., 95, 353-366, doi:10.1016/ j.atmosres.2009.09.013.

Brook, R. D., and Coauthors, 2010: Particulate matter air pollution and cardiovascular disease-An update to the scientific statement from the American Heart Association. Circulation, 121, 2331-2378, doi:10.1161/CIR.0b013e3181dbece1.

Correia, A. W., C. A. Pope III, D. W. Dockery, Y. Wang, M. Ezzati, and F. Dominici, 2013: The effect of air pollution control on life expectancy in the United States: An analysis of 545 US counties for the period 2000 to 2007. Epidemiology, 24, 23-31, doi:10.1097/EDE.0b013e3182770237.

Environmental Protection Agency, 2009: Air quality designations for the 2006 24-hour fine particle $\left(\mathrm{PM}_{2.5}\right)$ National Ambient Air Quality Standards: Final rule. 40 CFR Part 81, 94 pp. [Available online at http://www.gpo.gov/fdsys/pkg/FR-200911-13/pdf/E9-25711.pdf.]

Gillies, R. R., S.-Y. Wang, and M. R. Booth, 2010: Atmospheric scale interaction on wintertime Intermountain West low-level inversions. Wea. Forecasting, 25, 1196-1210, doi:10.1175/ 2010WAF2222380.1. 
and

,2012: Observational and synoptic analyses of the winter precipitation regime change over Utah. J. Climate, 25, 4679-4698, doi:10.1175/JCLI-D-11-00084.1.

Horton, D. E., C. B. Skinner, D. Singh, and N. S. Diffenbaugh, 2014: Occurrence and persistence of future atmospheric stagnation events. Nat. Climate Change, 4, 698-703, doi:10.1038/ nclimate2272.

Hurrell, J. W., 1995: Decadal trends in the North Atlantic Oscillation: Regional temperatures and precipitation. Science, $\mathbf{2 6 9}$, 676-679, doi:10.1126/science.269.5224.676.

Kalnay, E., and Coauthors, 1996: The NCEP/NCAR 40-Year Reanalysis Project. Bull. Amer. Meteor. Soc., 77, 437-471, doi:10.1175/1520-0477(1996)077<0437:TNYRP>2.0.CO;2.

Leung, L. R., and W. I. Gustafson, 2005: Potential regional climate change and implications to U.S. air quality. Geophys. Res. Lett., 32, L16711, doi:10.1029/2005GL022911.

Malek, E., T. Davis, R. S. Martin, and P. J. Silva, 2006: Meteorological and environmental aspects of one of the worst national air pollution episodes (January, 2004) in Logan, Cache Valley, Utah, USA. Atmos. Res., 79, 108-122, doi:10.1016/ j.atmosres.2005.05.003.

Martin, R. S., 2006: Cache Valley air quality studies: A summary of research conducted (through 2006). Utah State University Dept. of Civil and Environmental Engineering Rep., 81 pp. [Available online at http://www.deq.utah.gov/Pollutants/P/pm/pm25/cachevalley/ docs/2010/09Sep/CacheValleyAirQualityStudies2006.pdf.]
Moller, A., and R. R. Gillies, 2008: Utah Climate. 2nd ed. Utah State University, $109 \mathrm{pp}$.

Mozurkewich, M., 1993: The dissociation constant of ammonium nitrate and its dependence on temperature, relative humidity and particle size. Atmos. Environ., 27A, 261-270, doi:10.1016/ 0960-1686(93)90356-4.

Peacock, S., 2012: Projected twenty-first-century changes in temperature, precipitation, and snow cover over North America in CCSM4. J. Climate, 25, 4405-4429, doi:10.1175/JCLI-D-11-00214.1.

Silva, P. J., E. L. Vawdrey, M. Corbett, and M. Erupe, 2007: Fine particle concentrations and composition during wintertime inversions in Logan, Utah, USA. Atmos. Environ., 41, 54105422, doi:10.1016/j.atmosenv.2007.02.016.

Wang, S.-Y., R. R. Gillies, R. Martin, R. E. Davies, and M. R. Booth, 2012: Connecting subseasonal movements of the winter mean ridge in western North America to inversion climatology in Cache Valley, Utah. J. Appl. Meteor. Climatol., 51, 617-627, doi:10.1175/JAMC-D-11-0101.1.

,$- \ldots$, and H. van den Dool, 2014: On the yearly phase delay of winter intraseasonal mode in the western United States. Climate Dyn., 42, 1649-1664, doi:10.1007/s00382-013-1784-y.

Watterson, T. L., J. Sorensen, R. Martin, and R. A. Coulombe Jr., 2007: Effects of $\mathrm{PM}_{2.5}$ collected from Cache Valley Utah on genes associated with the inflammatory response in human lung cells. J. Toxicol. Environ. Health, 70A, 1731-1744, doi:10.1080/15287390701457746. 